\title{
Reform of Physical Talents Training of College Students Party Members Mi Zhou ${ }^{1, \text { a }}$ \\ ${ }^{1}$ Jiangxi Vocational College of Industry\& Engineering, Pingxiang, Jiangxi, 337000 \\ ${ }^{a}$ email
}

Keywords: Physical Education, College Students, Party Members

\begin{abstract}
Our Physical education offers professional sports for nearly 20 years, but is still in its infancy, there are many immature places. Current construction of sports relies mainly on the leapfrog development of mass sports, sports professionals is to promote the development of mass sports backbone, so to cultivate and foster a large-scale, structural optimization, rational layout, high-quality social sports talent need for current social sports professionals value demands to discuss the current state to encourage students to start their own businesses, and to give a certain amount of policy and financial support for sports professionals business model study. It helps to expand innovative training model and to broaden the Physical development of professional training.
\end{abstract}

\section{Introduction}

On february 22, 2012 issued by the Ministry of Education "on efforts to" undergraduate teaching project "National Students' Innovation and Entrepreneurship Training Program implementation of the notice" that the goal of the program is through the implementation of a national innovation and entrepreneurship students training program, Promoting College conversion of educational concepts, talents training mode reform, strengthening innovation and entrepreneurship training, to enhance college students innovation and entrepreneurship based on innovation, training to adapt to building an innovative country needs high-level innovative talents. Program includes innovative training programs, entrepreneurship training programs and business practices project categories. Talent is the first resource of economic and social development and national prosperity is an important driving force. Our offer professional sports for nearly 20 years, but is still in its infancy, there are many immature places. Current construction of sports power, rely mainly on the leapfrog development of mass sports, sports professionals is to promote the development of mass sports backbone, so to cultivate and foster a large-scale, structural optimization, rational layout, high-quality social sports talent need for current social sports professionals value demands to discuss the current state to encourage students to start their own businesses, and to give a certain amount of policy and financial support for sports professionals business model study help expand innovative training model, and to broaden the development of space Sports talents of Jian extension of its field of view is advantageous. This study is based on the basis of the above, by changing the past, a single professional sports training model, put forward innovative business model for Physical Education Majors culture, in order to seek to adapt to the needs of society, sports professionals entrepreneurship training mode of the times, for the future the research foundation, to provide reference for the relevant departments for the training of professionals in sport mode Jian new extension horizon.

\section{Current Situation of Sports Talents Training}

Since the founding of New China, college sports specialty and professional training objectives several changes to adjust to July 1998 enactment of the new professional directory, Department of Physical Education professional there are five kinds, namely physical education, sports training, social sports, Human Movement Science and traditional sports. College of Physical Education is provided through five years of construction and development, although has made great achievements, but there are still some problems to be solved.

Apparent lack of professional sports point of presence in the number of faculties and emphasize 
the consequences of ignoring widely designed in talents training specifications. This professional structure is difficult to adapt to social development and the diversification of today's demand for sports trend of diversification. Pressing social needs training, the development of higher PE may be the creation of new professions and professional direction according to the needs of society. For example, China's sports industry development plan in the initial stage, in order to accelerate the development of sports industry, requires a lot of sports not only understands but also understands the management of personnel practices. Our sports business and sports brokers is sorely lacking talent, but have not set Physical Education Major in professional training of such personnel. Try setting Public Administration (Sport Management), Journalism (Sports Journalism direction), tourism (sports travel direction) and other non-professional sports.

Sports, entertainment and sports career development, to train teachers of traditional sports professional impact, more diversified professional setting. In the largest professional under the small professional training so that students can master both the professional knowledge and skills in certain areas of social needs, but also meet the needs of a wide range of professional occupations. College of Sports Training Major in the past simply to coach dominated monoculture targets have been difficult to meet the high professional society today demands professional sports training should broaden the professional caliber, training target transition from one target to multiple targets. Teachers of Physical Education teacher professional should be stable under the main channel, open non-teacher professional auxiliary channels. Undergraduate PE specialty should go deep foundation, wide professional road widening professional direction, dilute the boundaries, open basis, with the first two years and a half years learning basic course and the basic course, after a year and a half time for professional training, forming a thick foundation of mutual coverage of culture in the form of professional caliber wide, so that students can improve their knowledge structure, foundation and capacity for sustainable development, based in the community.

Chinese Sports have 241 undergraduate majors and 138 professional education major, professional sports training 36 points, PE 31 professional points, Human Movement Science 14 professional points, majoring in traditional sports professional 22 points. Not difficult to find, our college sports professional specialty limited to competitive sports and school sports two major areas of service to the community sports rarely involved in this vast market. Bachelor of Sports uneven distribution of existing professional, professional transition has lagged far behind the pace of development, has resulted in conflicts of higher physical education and social needs. Thus, China's professional sports should take full account of higher development of our economic, social, forward thinking professional sports school direction, and have a comprehensive focus on the urgent need to foster social sports professionals. Professional adjustment should be bold, to strengthen the transformation of the old and the new professional construction to meet the needs of society and the times. Discussion for professional settings, not just professional set list also includes the name of the professional or professional direction of analysis, professional training specifications, namely human knowledge, structure and capacity of the structure design and so on.

\section{PE Talents Training Reform Research}

PE Majors in the choice of business model, the first is to provide sufficient driving force for entrepreneurship for college students, so as to be able to make the initiative to start a business, from the following aspects to College Students: First, schools should be encouraged strengthening entrepreneurship and entrepreneurial education combined, not only to provide students with lectures several successful entrepreneurs, it is not sure, but you need to students Party entrepreneurship education to fall into specific lessons, each link can go one by one correspondence, should be taught related courses, lectures and then again according to the needs of the course, in this regard invites entrepreneurs to successful school lectures, so that students will be able to more easily business knowledge learned in the classroom to make full use of lectures in practical cases to go to stimulate students' enthusiasm for entrepreneurship; second, employment guidance, to change the concept of employment of university students, need to actively promote students to actively participate in the business environment to go, and create innovative academic atmosphere, so that students 
understand the importance and necessity in today's world of entrepreneurship; third, to encourage students start school at the same time, can not be pursued blindly, say what each student needs to try entrepreneurial activities, but by Jian beginning and entrepreneurship seminar organized entrepreneurship courses, and then based on the student's self-will, to guide students to go to work, and actively to stimulate students who have entrepreneurial passion and entrepreneurial practice for these students provide a platform and platform Create hoof election and the establishment of incentives.

College Students Party Members now for entrepreneurship support policies, including the following: business plan competition organized college students, college students venture to carry out quality development activities, business students organized lectures, students start to hold training activities Building University Science Park, Innovation Park. Pioneer Park student is entrepreneurial campus practice base, to provide students with practical platform for entrepreneurship in school; Pioneer Park incubator having a function within graduate students and students a year to provide business services. School founded by Pioneer Park, Pioneer Park is jointly managed by the Communist Youth League and employment at the specific duties by the business park management services center and management service centers are located in the Communist Youth League. Developed business park access system and associate the system, management system, mentoring regulations, legal advice system, financial institutions and loan evaluation system. The business park on campus is basically to establish a new business, everything from scratch, in this case can be divided into the following types:

First, the market discovery mode, mainly refers to college students through the investigation found that the existence of market opportunities, including self with talent, existing products in another area of the market space. Students can take advantage of their expertise to find business opportunities, entrepreneurship, and learn from the experience of other companies conduct business management. This model is relatively simple, and clear the project location, experience can refer to, more suitable for business students who play their own advantages.

Second, technological innovation model, with patented technology refers to college students or own invention, through financing, the creation of enterprises. Because college students only have technical achievements, in order to succeed you must also venture capital, management team and other aspects of cooperation, therefore, are generally assessed by patents and attract investment, joint-stock business model and scientific management. This model is the most typical mode of independent business, enabling technology into productivity, generates a good market value and social value, so that students get the maximum of expertise play.

Thirdly, the interests of innovation model, refers to some college students by means of advanced methods to play the traditional role of something, we discover new interests and entrepreneurial. This mode is less demanding for entrepreneurs, university students only need to be good at observation, found links between different things, the latter can take the form of the creation of the partnership and other companies. New business is purely business, new companies need to have new ideas, ideas, is creative, but creativity is actually mostly from the details of life, is closely related to their own lives hobby, we need to pay attention to college students everywhere. Although college students active thinking, the foundation has to be creative, but after the birth of creativity, but also need to put into practice before the detailed planning and evaluation, so that implementation of the plan step by step, there shall not here, guarantee the success of creative energy into entrepreneurship.

Schools and enterprises to build a model school and the companies jointly established entrepreneurship training base, to provide students with entrepreneurship training platform in the enterprise. A way for students in business for one year is internship. Internship contract is to determine the interests of both, to distinguish the respective responsibilities of schools and enterprises. Second, the use of national support policies for business students, the establishment of small businesses in the community is under the guidance of national policy by the school businesses. Development of evaluation criteria outside of entrepreneurship, entrepreneurship program standardizes enterprise behavior and the entrepreneurial process. In the establishment of small 
businesses, franchising is the most appropriate business students.

\section{Conclusion}

College of Physical Education teaching content is obsolete, behind the situation and the curriculum reform is to reflect modern scientific achievements, expand new knowledge, to delete obsolete, outdated content. Knowledge structure irrational is the main problem of the Faculty of Physical Higher Education, strengthen pre-service teachers of Physical Training; enrollment and the reform of PE culture and the strengthen in-service teacher training has been on the agenda.

\section{Acknowledgements}

2015 Education Department of Jiangxi Party building issues (JXGXDJKT.GH-201513), 2014 Jiangxi Education Reform Project (JXJG-14-22-6), Jiangxi IP soft science research project (ZR201610)

\section{References}

[1] Wang Jiang. Changes and Enlightenment Chinese Sports Universities specialty [J]. Shanghai Institute of Physical Education, 1999, (4): 7-11.

[2] Li Xianguo. Sports Department of Curriculum and graduate employment situation [J]. Xi'an Institute of Physical Education, 2003, (1): 92-94.

[3] Bai Wenfei. Sports College Graduates Employment Problem Analysis [J]. China Sport Science and Technology, 2002, (3): 52-55.

[4] Zhao Jianhua. Challenges and countermeasures of higher physical education major [J]. Physical Education, 2001, (5): 14-16.

[5] Qu Zonghu. 21 century physical education major development direction and mode Reflections [J]. Beijing Normal University Physical Education, 1996, (1): 14-19. 